\title{
QUANTIFICAÇÃO DE POLIFENÓIS E DIGESTIBILIDADE PROTÉICA DE FAMÍLIAS DE FEIJOEIRO COMUM
}

\author{
CARLA VIVIANE C. EGG MENDONÇA ${ }^{1}$ \\ CELESTE M. PATTO DE ABREU ${ }^{2}$ \\ ANGELITA DUARTE CORRÊA ${ }^{3}$ \\ CUSTÓDIO DONIZETE DOS SANTOS ${ }^{3}$ \\ AUGUSTO RAMALHO DE MORAIS ${ }^{4}$
}

\begin{abstract}
RESUMO - O feijão é um dos alimentos encontrados em maior quantidade em todo o território nacional e é cultivado em quase todos os Estados. É uma importante fonte protéica na dieta do povo brasileiro, estando presente na alimentação da população rural e urbana. No presente trabalho, quantificaram-se os polifenóis e determinaram-se os níveis de digestibilidade protéica de cem famílias de feijoeiro comum (Phaseolus vulgaris
\end{abstract}

L.) obtidas do cruzamento entre os genótipos Amarelinho e CI 107. Os polifenóis afetam a qualidade do feijão, causando escurecimento, endurecimento e, ainda, podem reduzir a digestibilidade protéica. Pelos resultados obtidos, pôde-se encontrar 13 famílias com teores reduzidos de polifenóis e boa digestibilidade protéica in vitro, as quais poderão ser utilizadas em programas de melhoramento dessa importante cultura.

TERMOS PARA INDEXAÇÃO: Feijão, Phaseolus vulgaris.

\section{POLYPHENOL QUANTIFICATION AND PROTEIN DIGESTIBILITY IN COMMON BEAN LINEAGES}

\begin{abstract}
Common beans are one of the most important food crops in Brazil and are cultivated in almost all Brazilian states. It is an important protein source for Brazilian people in both rural and urban areas. The present work performed the quantification of phenolic compounds and in vitro protein digestibility of one hundred common bean lines (Phaseolus vulgaris L.) obtained by crossing the genotypes "Amarelinho"
\end{abstract}

INDEX TERMS: Common bean, Phaseolus vulgaris.

\section{INTRODUÇÃO}

Entre os vegetais, as leguminosas constituem excelente fonte de proteínas e carboidratos, sendo uma das principais alternativas como suprimento protéico em áreas onde fontes de proteína animal são escassas ou caras (LAJOLO et al., 1996).

Na alimentação dos brasileiros, o feijão (Phaseolus vulgaris L.) é a principal fonte de proteína (20 a and CI 107. The results suggested that the phenolic compounds affected bean cooking traits and quality through darkening and hardening of the seed coat. Phenolic compounds also influenced the in vitro protein digestibility. It was observed that all 13 lines presented low levels of phenolic compounds and good in vitro protein digestibility and, as a result, must be incorporated in the breeding programs for this important crop.

$28 \%$ ), seguido, em importância, pela carne bovina. Além de ser uma cultura de grande expressão socioeconômica, a proteína do feijão tem um custo menor de produção do que a proteína animal (LAJOLO et al.,1996).

Os polifenóis abrangem um extenso grupo de substâncias que possuem um anel aromático contendo pelo menos uma hidroxila (RIBÉREAU-GAYON, 1972). Em leguminosas, os taninos são os polifenóis de

1. Mestranda em Agroquímica e Agrobioquímica. Bolsista CNPq.

2. Professor do Departamento de Química da UNIVERSIDADE FEDERAL DE LAVRAS/UFLA - Caixa Postal 37 37200-000 - Lavras, MG. Bolsista Produtividade CNPq. celeste@ufla.br

3. Professores do Departamento de Química/UFLA.

4. Professor do Departamento de Ciências Exatas/UFLA. 
maior importância, pois além de possíveis efeitos sobre a biodisponibilidade de minerais, a sua importância nutricional parece estar mais associada à sua influência sobre a digestibilidade das proteínas. Os taninos do feijão possuem a capacidade de formar complexos com a faseolina in vitro, basicamente por meio de interações hidrofóbicas, produzindo uma diminuição significativa na digestibilidade dessa proteína, tanto na forma nativa como na desnaturada, mesmo em concentrações elevadas de proteases (LAJOLO et al., 1996).

O conteúdo dos polifenóis varia de acordo com a coloração da casca onde se encontram. Em feijões marrons, pretos, vermelhos e brancos, o teor médio é de $7,8,6,6,12,6$ e 2,3mg/g de equivalentes de catequina, respectivamente (BRESSANI, 1993).

Em amostras de feijão das cultivares Moruna 80, Aroara 80 e Rico 23, o teor de polifenóis totais foi de $1,5 \mathrm{mg} / \mathrm{g}, 3,3 \mathrm{mg} / \mathrm{g}$ e $2,7 \mathrm{mg} / \mathrm{g}$, respectivamente, em equivalentes de catequina (COELHO, 1987). Elias et al. (1979) trabalharam com amostras de feijão comum e encontraram, em equivalentes de ácido tânico/g de amostra, 3,8 e 3,9 para duas cultivares de feijão branco; 9,3 para uma vermelha e 9,2 e 6,7 para duas cultivares pretas.

Também se observa uma correlação negativa entre o conteúdo de taninos e a digestibilidade protéica in vivo; porém, os mecanismos responsáveis por esse efeito ainda não foram elucidados. Segundo Bressani (1993), as hipóteses acerca de sua ação seriam a formação de complexos com as proteínas do feijão durante o cozimento ou consumo e/ou com as enzimas digestivas levando à sua inativação.

A digestibilidade protéica é um parâmetro nutricional que avalia o aproveitamento de uma fonte protéica, podendo ser influenciada por vários compostosinibidores de enzimas digestivas, hemaglutininas, polifenóis, etc. A digestibilidade protéica, avaliada em diferentes experimentos, tanto in vitro como em animais, situa-se entre $40 \%$ e $70 \%$ (SGARBIERI et al., 1979), sendo baixa em humanos (cerca de 55\%) (BRESSANI, 1983). A baixa digestibilidade das proteínas de feijão, quando comparada às proteínas animais, é um dos seus problemas nutricionais.

A digestibilidade varia conforme a cultivar, sendo a digestibilidade dos grãos brancos melhor que a dos vermelhos (REDDY e PIERSON, 1985); fato associado ao teor e à natureza dos taninos da casca das cultivares coloridas (AW e SWANSON, 1985). Segundo Hernández et al. (1984), o feijão preto apresentou a menor digestibilidade.
Os polifenóis livres inibem várias enzimas digestivas em sistemas in vitro. Esses compostos estão envolvidos nas ligações da lignina com os carboidratos da parede celular e essa associação reduz a digestibilidade. Há também o fato de os fenóis simples precipitarem as proteínas pela formação de um revestimento hidrofóbico, semelhante à complexação taninos-proteínas (LOPES, 1990).

Bressani (1993) apontou a reduzida digestibilidade das proteínas do feijão (e de outras leguminosas) como sendo multicausal, sugerindo a ação de fatores ligados à casca (taninos), aos cotilédones (inibidores de natureza protéica, taninos, fitatos, inibidores de proteases) e ao processamento e armazenamento. Para Badiale (1979), a baixa digestibilidade dos feijões se deve a dois fatos: passagem rápida dos grãos cozidos pelo tubo digestivo, o que impede a ação de enzimas proteolíticas ou o fato de as proteínas dos grãos serem resistentes à proteólise enzimática. Segundo Lajolo et al. (1996), o problema está nas moléculas protéicas, como elas interagem entre si e com outros componentes e como essas interações ocorrem no armazenamento e processo industrial.

Levando em conta o exposto, com este trabalho objetivou-se fornecer subsídios aos melhoristas e estudar o conteúdo de polifenóis e a digestibilidade protéica in vitro em cem famílias de feijoeiro comum obtidas do cruzamento dos genótipos Amarelinho e CI 107, para obtenção de melhores famílias para estudos futuros.

\section{MATERIAL E MÉTODOS}

\section{Matéria-prima}

Neste trabalho foram utilizadas cem famílias de feijoeiro comum obtidas do cruzamento entre os genótipos Amarelinho e CI-107. Essas famílias foram fornecidas pelo Setor de Genética e Melhoramento de Plantas do Departamento de Biologia da Universidade Federal de Lavras (UFLA) / Lavras - MG, sendo cultivadas no Setor Experimental daquele Departamento, na safra das águas e colhidas em fevereiro de 2000.

A linhagem Amarelinho apresenta grão amarelo, hábito de crescimento tipo III, ciclo de 90 dias, porte prostrado e baixa absorção de água. A linhagem CI-107 apresenta grão tipo carioca, hábito de crescimento tipo III, ciclo normal (90 dias), porte prostrado e boa absorção de água (ESTEVES, 2000).

Os grãos foram moídos em moinho refrigerado e as farinhas, armazenadas em frasco de vidro, em temperatura ambiente, até a realização das análises. 


\section{Umidade}

Para a transformação dos dados em base seca, a farinha foi seca, em estufa a $105^{\circ} \mathrm{C}$, até peso constante (AOAC, 1990).

\section{Polifenóis}

Os polifenóis foram extraídos com metanol a $80 \%$, em banho-maria a $80^{\circ} \mathrm{C}$ com refluxo, por 15 minutos. $\mathrm{O}$ sobrenadante foi recolhido, evaporado em banho-maria até quase a secura e transferido para balão volumétrico, completando-se o volume com água e filtrando-se posteriormente (HAGERMAN e BUTLER, 1980).

Para determinação dos polifenóis totais, utilizou-se o método descrito por Swain e Hillis (1959). Os reagentes de Folin-Denis e a solução saturada de carbonato de sódio foram preparados segundo a AOAC (1990). O método baseia-se na oxidação de hidroxilas fenólicas pelo reagente de Folin-Denis, em meio alcalino, com produção de composto de coloração azul, que foi medido em espectofotômetro a $750 \mathrm{~nm}$. O ácido tânico foi utilizado como padrão. Os resultados foram expressos em miligramas de equivalentes do ácido tânico por 100 gramas de matéria seca.

\section{Digestibilidade protéica in vitro}

Empregou-se a técnica descrita por Akesson e Stahmann (1964) para a determinação da digestibilidade protéica in vitro. A farinha (com teor de nitrogênio conhecido) foi digerida com a pepsina e pancreatina, em seus pHs ótimos. A reação foi interrompida por adição de ácido tricloroacético. Após centrifugação, dosou-se o nitrogênio no sobrenadante. A caseína foi utilizada como controle. A digestibilidade encontrada para caseína foi tomada como padrão e seu valor considerado como $100 \%$. As digestibilidades das farinhas foram corrigidas em relação à caseína e os resultados expressos em porcentagem em base seca.

\section{Delineamento experimental e Análise estatística}

O delineamento experimental utilizado foi o inteiramente casualizado, com duas repetições e os tratamentos foram constituídos pelas cem famílias obtidas do cruzamento dos genótipos Amarelinho e CI 107.

Quando os efeitos de tratamentos foram significativos $(\mathrm{P} \leq 0,05)$, utilizou-se o Teste de Scott e Knott (5\%) para comparação entre as médias das famílias ou tratamentos (MORAIS, 2000). As análises de variância e teste de médias foram realizados utilizando o pacote estatístico SISVAR (Sistema de Análise de Variância).

\section{RESULTADOS E DISCUSSÃO}

\section{Polifenóis}

$\mathrm{Na}$ Tabela 1, pode-se observar que os teores (mg de equivalentes de ácido tânico/100 g de farinha em base seca) de polifenóis diferiram significativamente entre as famílias de feijoeiro comum testadas.

As famílias testadas foram agrupadas pelo Teste de Scott \& Knott em seis categorias (Figura 1), as quais apresentaram teores médios que variaram de 257,91 a $1.446,80 \mathrm{mg}$ de equivalentes de ácido tânico/100g de farinha em base seca . Dessas famílias, 63\% (Grupos 3, 4,5 e 6) apresentaram teores de polifenóis acima de 616,26 mg de equivalentes de ácido tânico/100g de farinha em base seca. De acordo com os teores de polifenóis encontrados por Elias et al. (1979), Coelho (1987) e Bressani (1993), os teores dessas famílias são elevados e podem ser melhorados geneticamente.

Das famílias estudadas, 32\% apresentaram teores de polifenóis de acordo com os encontrados por Rios (2000), as quais situaram-se entre 410 e $450 \mathrm{mg}$ de equivalente de ácido tânico/ $100 \mathrm{~g}$ de tecido em base seca para as cultivares Carioca, CI 128 e ESAL 550, logo após a colheita. Dessas famílias, $49 \%$ apresentaram teores de polifenóis de acordo com os encontrados por Esteves (2000), que foram teores médios de 830,71 e $600,00 \mathrm{mg}$ de equivalentes de ácido tânico/100g de farinha em base seca para as linhagens Amarelinho e CI 107, respectivamente.

Em razão da variação genética ocorrida durante a recombinação, pode-se observar que 36 e $29 \%$ das famílias apresentaram, respectivamente, teores menores e maiores de polifenóis que aqueles apresentados pelos pais (Amarelinho e CI 107), sugerindo a necessidade da continuação de melhoramento genético para essa característica.

\section{Digestibilidade protéica in vitro}

Na Tabela 2 é apresentada a digestibilidade protéica in vitro das cem famílias estudadas.

$\mathrm{Na}$ Figura 2 pode-se observar o agrupamento das famílias pelo Teste de Scott \& Knott, sendo observados teores médios de digestibilidade protéica in vitro de 47 , 53,59 , e $66 \%$. Observou-se que $69 \%$ das famílias apresentaram a digestibilidade protéica in vitro acima de $51,40 \%$ (Grupos 2, 3 e 4). Todas as famílias estudadas apresentaram teores acima de $40 \%$. 
TABELA 1 - Teores de polifenóis (mg de equivalentes de ácido tânico/100g de farinha em base seca) em 100 famílias de feijoeiro comum oriundas do cruzamento entre os genótipos Amarelinho e CI 107.

\begin{tabular}{|c|c|c|c|c|c|c|c|c|c|c|c|c|c|}
\hline FAMÍLA & POLIFENÓIS & FAMÍLI & POLIFE & NÓIS & FAMÍLA & POLIFE & NÓIS & FAMÍL & POLFE & NÓIS & FAMÍL & POLIFE & NÓIS \\
\hline 1 & $914,98 \mathrm{D}^{1}$ & 21 & 387,23 & B & 41 & 880,78 & D & 61 & 841,36 & $\mathrm{C}$ & 81 & 902,82 & D \\
\hline 2 & $763,43 \quad \mathrm{C}$ & 22 & 270,95 & A & 42 & 737,30 & $\mathrm{C}$ & 62 & 625,26 & $\mathrm{C}$ & 82 & 794,39 & $\mathrm{C}$ \\
\hline 3 & $1361,77 \mathrm{~F}$ & 23 & 281,78 & A & 43 & 733,72 & $\mathrm{C}$ & 63 & 419,84 & B & 83 & 1096,63 & $\mathrm{D}$ \\
\hline 4 & $1531,83 \mathrm{~F}$ & 24 & 510,89 & B & 44 & 535,95 & B & 64 & 883,63 & $\mathrm{D}$ & 84 & 750,92 & $\mathrm{C}$ \\
\hline 5 & $734,77 \quad \mathrm{C}$ & 25 & 221,96 & A & 45 & 976,90 & $\mathrm{D}$ & 65 & 254,67 & A & 85 & 767,80 & $\mathrm{C}$ \\
\hline 6 & $696,60 \mathrm{C}$ & 26 & 487,62 & B & 46 & 768,12 & $\mathrm{C}$ & 66 & 667,39 & $\mathrm{C}$ & 86 & 469,98 & B \\
\hline 7 & $707,09 \quad \mathrm{C}$ & 27 & 252,75 & A & 47 & 744,79 & $\mathrm{C}$ & 67 & 643,35 & $\mathrm{C}$ & 87 & 863,58 & $\mathrm{C}$ \\
\hline 8 & $883,20 \quad \mathrm{D}$ & 28 & 344,98 & A & 48 & 494,52 & B & 68 & 616,26 & $\mathrm{C}$ & 88 & 300,29 & A \\
\hline 9 & $742,16 \quad \mathrm{C}$ & 29 & 1040,41 & & 49 & 736,13 & $\mathrm{C}$ & 69 & 697,05 & $\mathrm{C}$ & 89 & 930,40 & $\mathrm{D}$ \\
\hline 10 & $866,71 \mathrm{C}$ & 30 & 1220,38 & & 50 & 956,42 & D & 70 & 165,35 & A & 90 & 675,54 & $\mathrm{C}$ \\
\hline 11 & $689,66 \mathrm{C}$ & 31 & 1133,01 & E & 51 & 794,79 & $\mathrm{C}$ & 71 & 160,24 & A & 91 & 751,69 & $\mathrm{C}$ \\
\hline 12 & $723,91 \quad \mathrm{C}$ & 32 & 1177,20 & & 52 & 456,09 & B & 72 & 625,86 & $\mathrm{C}$ & 92 & 880,19 & $\mathrm{D}$ \\
\hline 13 & $825,47 \quad \mathrm{C}$ & 33 & 1038,97 & & 53 & 944,65 & D & 73 & 924,85 & $\mathrm{D}$ & 93 & 185,16 & A \\
\hline 14 & $684,12 \mathrm{C}$ & 34 & 1004,28 & D & 54 & 511,94 & B & 74 & 570,88 & B & 94 & 466,12 & B \\
\hline 15 & $800,99 \mathrm{C}$ & 35 & 717,73 & $\mathrm{C}$ & 55 & 694,69 & $\mathrm{C}$ & 75 & 283,84 & A & 95 & 374,88 & B \\
\hline 16 & $638,58 \mathrm{C}$ & 36 & 761,70 & $\mathrm{C}$ & 56 & 582,82 & B & 76 & 788,99 & $\mathrm{C}$ & 96 & 374,95 & B \\
\hline 17 & $291,90 \mathrm{~A}$ & 37 & 271,32 & A & 57 & 456,56 & B & 77 & 891,69 & $\mathrm{D}$ & 97 & 979,07 & $\mathrm{D}$ \\
\hline 18 & 160,09 A & 38 & 342,30 & A & 58 & 290,49 & A & 78 & 850,15 & $\mathrm{C}$ & 98 & 696,17 & $\mathrm{C}$ \\
\hline 19 & 309,14 A & 39 & 168,06 & A & 59 & 402,88 & B & 79 & 916,98 & $\mathrm{D}$ & 99 & 345,76 & A \\
\hline 20 & 387,99 В & 40 & 673,29 & $\mathrm{C}$ & 60 & 880,40 & $\mathrm{D}$ & 80 & 915,57 & D & 100 & 385,32 & B \\
\hline
\end{tabular}

${ }^{1}$ Médias seguidas de mesmas letras não diferem entre si pelo Teste de Scott-Knott, a $5 \%$ de probabilidade.

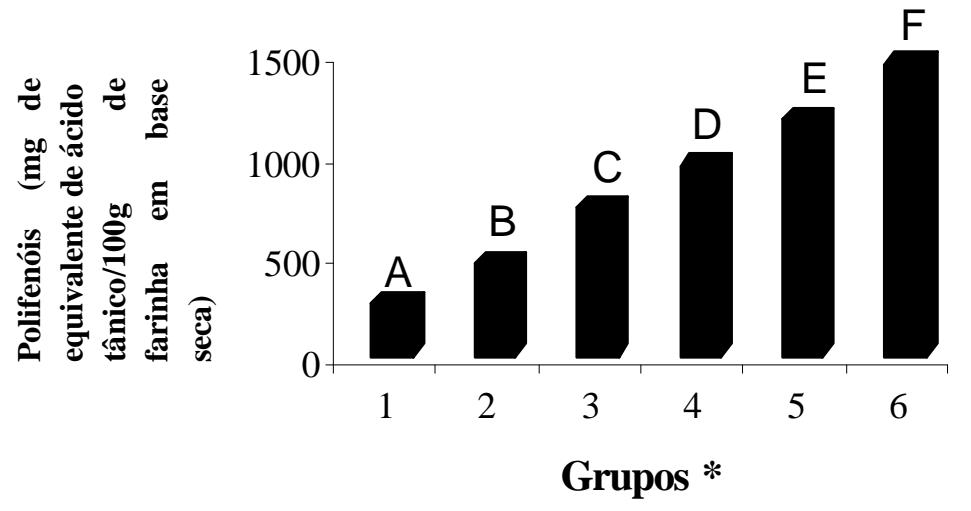

FIGURA 1 - Teores de polifenóis em cem famílias de feijoeiro comum obtidas no cruzamento dos genótipos Amarelinho e CI 107 agrupadas pelo Teste de Scott \& Knott. *Grupos: 1 (19 famílias); 2 (18 famílias); 3 (38famílias); 4 (20 famílias); 5 (3 famílias); 6 (2 famílias). 
TABELA 2 - Digestibilidade protéica in vitro $(\%)^{1}$ de cem famílias de feijoeiro comum obtidas do cruzamento entre os genótipos Amarelinho e CI 107.

\begin{tabular}{|c|c|c|c|c|c|c|c|c|c|}
\hline FAMÍLIA & DIGEST. ${ }^{2}$ & FAMÍLIA & DIGEST. $^{2}$ & FAMÍLIA & DIGEST. ${ }^{2}$ & FAMÍLIA & DIGEST. $^{2}$ & FAMÍLIA & DIGEST. \\
\hline 1 & $68,90 \mathrm{D}^{3}$ & 21 & $59,50 \mathrm{C}$ & 41 & $59,90 \mathrm{C}$ & 61 & $58,90 \mathrm{C}$ & 81 & $50,65 \mathrm{~A}$ \\
\hline 2 & $61,25 \mathrm{C}$ & 22 & $64,50 \mathrm{D}$ & 42 & $53,00 \mathrm{~B}$ & 62 & $64,20 \mathrm{D}$ & 82 & $51,40 \mathrm{~B}$ \\
\hline 3 & $67,80 \mathrm{D}$ & 23 & $56,90 \mathrm{C}$ & 43 & $56,70 \mathrm{C}$ & 63 & $59,95 \mathrm{C}$ & 83 & $48,10 \mathrm{~A}$ \\
\hline 4 & 67,75 D & 24 & 56,25 B & 44 & 54,50 B & 64 & $61,70 \mathrm{C}$ & 84 & $46,20 \mathrm{~A}$ \\
\hline 5 & $71,30 \mathrm{D}$ & 25 & $56,00 \mathrm{~B}$ & 45 & 54,45 B & 65 & $63,65 \mathrm{D}$ & 85 & $44,50 \mathrm{~A}$ \\
\hline 6 & $62,25 \mathrm{C}$ & 26 & $57,95 \mathrm{C}$ & 46 & $48,50 \mathrm{~A}$ & 66 & $55,60 \mathrm{~B}$ & 86 & $44,70 \mathrm{~A}$ \\
\hline 7 & $68,10 \mathrm{D}$ & 27 & $58,40 \mathrm{C}$ & 47 & $62,85 \mathrm{C}$ & 67 & $45,75 \mathrm{~A}$ & 87 & $46,15 \mathrm{~A}$ \\
\hline 8 & $73,00 \mathrm{D}$ & 28 & $63,65 \mathrm{D}$ & 48 & $49,15 \mathrm{~A}$ & 68 & $49,95 \mathrm{~A}$ & 88 & $47,85 \mathrm{~A}$ \\
\hline 9 & $62,00 \mathrm{C}$ & 29 & $60,30 \mathrm{C}$ & 49 & $58,30 \mathrm{C}$ & 69 & 52,35 B & 89 & $46,60 \mathrm{~A}$ \\
\hline 10 & $67,95 \mathrm{D}$ & 30 & $56,95 \mathrm{C}$ & 50 & $65,45 \mathrm{D}$ & 70 & 55,65 B & 90 & $48,00 \mathrm{~A}$ \\
\hline 11 & 54,85 B & 31 & 54,95 B & 51 & $47,60 \mathrm{~A}$ & 71 & $54,20 \mathrm{~B}$ & 91 & $58,60 \mathrm{C}$ \\
\hline 12 & 55,35 B & 32 & $59,75 \mathrm{C}$ & 52 & $49,25 \mathrm{~A}$ & 72 & $53,90 \mathrm{~B}$ & 92 & $62,15 \mathrm{C}$ \\
\hline 13 & $48,90 \mathrm{~A}$ & 33 & $51,95 \mathrm{~B}$ & 53 & $50,05 \mathrm{~A}$ & 73 & $49,45 \mathrm{~A}$ & 93 & $55,25 \mathrm{~B}$ \\
\hline 14 & 54,35 B & 34 & $53,90 \mathrm{~B}$ & 54 & $47,65 \mathrm{~A}$ & 74 & $49,95 \mathrm{~A}$ & 94 & $52,60 \mathrm{~B}$ \\
\hline 15 & $49,20 \mathrm{~A}$ & 35 & $59,10 \mathrm{C}$ & 55 & $50,25 \mathrm{~A}$ & 75 & 51,65 B & 95 & $53,20 \mathrm{~B}$ \\
\hline 16 & $51,60 \mathrm{~B}$ & 36 & $46,85 \mathrm{~A}$ & 56 & 54,05 B & 76 & $58,55 \mathrm{C}$ & 96 & $47,10 \mathrm{~A}$ \\
\hline 17 & $63,10 \mathrm{C}$ & 37 & $57,95 \mathrm{C}$ & 57 & 54,35 B & 77 & $61,05 \mathrm{C}$ & 97 & $47,50 \mathrm{~A}$ \\
\hline 18 & $51,50 \mathrm{~B}$ & 38 & $45,85 \mathrm{~A}$ & 58 & $52,80 \mathrm{~B}$ & 78 & $60,45 \mathrm{C}$ & 98 & $46,45 \mathrm{~A}$ \\
\hline 19 & 54,70 B & 39 & 55,05 B & 59 & $45,70 \mathrm{~A}$ & 79 & $63,90 \mathrm{D}$ & 99 & $50,65 \mathrm{~A}$ \\
\hline 20 & 53,05 B & 40 & $48,55 \mathrm{~A}$ & 60 & 54,85 B & 80 & $58,70 \mathrm{C}$ & 100 & $42,95 \mathrm{~A}$ \\
\hline
\end{tabular}

${ }^{1}$ Valores corrigidos para caseína considerada $100 \%$ digerível.

${ }^{2}$ Digest. $=$ Digestibilidade

${ }^{3}$ Médias seguidas de mesmas letras não diferem entre si pelo Teste de Scott-Knott, a $5 \%$ de probabilidade.

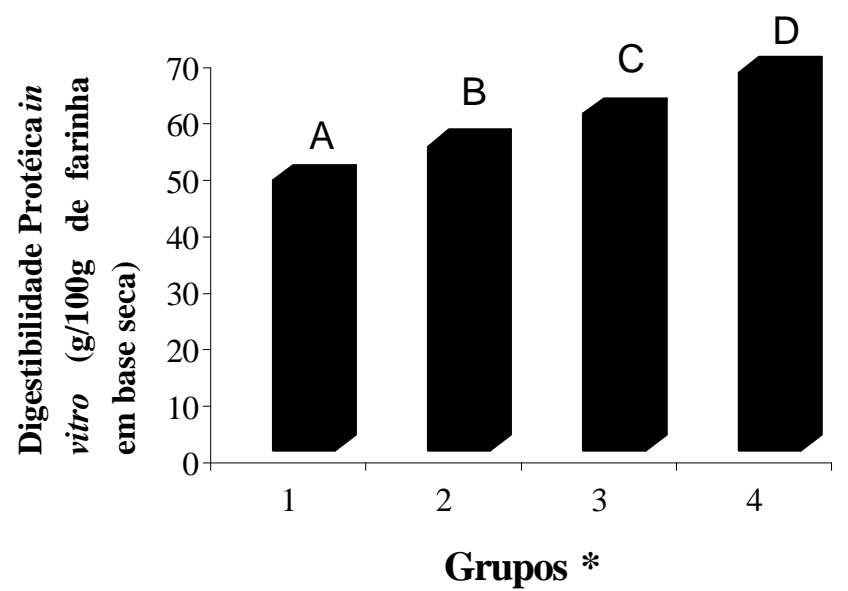

FIGURA 2 - Teores médios de digestibilidade (\%) em cem famílias de feijoeiro comum obtidas do cruzamento dos genótipos Amarelinho e CI 107. * Grupos: 1 (31 famílias); 2 (30 famílias); 3 (26 famílias); 4 (13 famílias).

Ciênc. agrotec., Lavras. V.27, n.4, p.858-864, jul./ago., 2003 
Os dados apresentados neste trabalho corroboram com os obtidos por Esteves (2000), que encontrou 64,38\% (Amarelinho) e 49,88\% (CI 107), e Sgarbieri et al. (1979), que encontraram valores situados entre $40 \%$ e $70 \%$, avaliando a digestibilidade tanto in vitro como em animais.

Bressani et al. (1988) concluíram que uma elevada concentração de compostos fenólicos, como ácido tânico ou catequinona, no feijoeiro comum, está altamente associada ao aumento do nitrogênio fecal e, assim, à redução da digestibilidade protéica em seres humanos. Os mesmos autores sugerem dois mecanismos que podem explicar o efeito de polifenóis na redução da digestibilidade protéica: a reação entre as proteínas e os fenóis durante o processamento do feijão e/ou entre os fenóis e as enzimas presentes no trato digestivo dos animais. Esses autores demonstraram, também, que a influência da concentração de taninos na digestibilidade da proteína e qualidade do feijão expressa-se pela correlação negativa entre a digestibilidade in vitro e o teor de taninos presentes no produto.

Não se sabe com certeza se a baixa digestibilidade é causada pelo funcionamento muito rápido do intestino ou por resistência das proteínas do feijão à hidrólise das enzimas gastrointestinais. Numerosos estudos confirmam o fato de que o inibidor de proteases é termolábil, de modo que não poderia ser responsável pela baixa digestibilidade das proteínas do feijão cozido (GOMEZ-BRENES et al., 1983).

Fukuda et al. (1982) determinaram a digestibilidade de sete cultivares de feijão, sendo três de cor preta, duas roxas e duas brancas. Os valores encontrados para a digestibilidade aparente variaram de $47,2 \%$ a $61,9 \%$ no feijão cru e de $65,6 \%$ a $76,6 \%$ para o feijão submetido à cocção. Observaram certa tendência indicando que a proteína do feijão branco é mais digerível que a do feijão preto e roxo. Sugeriram, ainda, que o feijão cozido tem um valor nutricional baixo, como conseqüência de fatores antinutricionais remanescentes, que estariam afetando a digestibilidade da proteína e sua deficiência natural de aminoácidos sulfurados. Sugeriram, também, que a digestibilidade aparente pode estar relacionada à estrutura da proteína, visto que os fatores antinutricionais são termolábeis e, portanto, são destruídos ou inativados parcial ou totalmente durante a cocção.

\section{CONCLUSÃO}

Pelos resultados obtidos e nas condições experimentais utilizadas no presente trabalho, pode-se concluir que: a) Mais de $50 \%$ das famílias apresentam elevados teores de polifenóis;

b) As cem famílias estudadas apresentam digestibilidade dentro da faixa encontrada para feijões, que é de $40 \%$ a $70 \%$.

c) As famílias que apresentam baixos teores de polifenóis e boa digestibilidade são: 17, 18, 22, 23, 25, $27,37,58,65,70,71,75$ e 88 , perfazendo um total de $13 \%$ de famílias que merecem atenção para a continuação de melhoramentos futuros.

\section{REFERÊNCIAS BIBLIOGRÁFICAS}

AKESSON, W. R.; STAHMANN, M. A. A pepsin pancreatin digest index of protein quality evaluation. Journal of Nutrition, Buthesda, v. 83, p. 257-261, 1964.

ASSOCIATION OF OFFICIAL ANALYTICAL CHEMISTS. Official methods of analysis of association of analitic chemists. 15. ed. Washington, 1990.

AW, T. L.; SWANSON, B. G. Influence of tannins on Phaseolus vulgaris protein digestibility and quality. Journal of Food Science, Chicago, v. 50, p. 67-71, Jan./Feb. 1985.

BADIALE, E. Variação de metionina em feijões (Phaseolus vulgaris L.) armazenados. 1979. 99 f. Dissertação (Mestrado em Ciências dos Alimentos) - Universidade Estadual de Campinas, Campinas, 1979.

BRESSANI, R. Grain quality of common beans. Food Reviews International, New York, v. 9, p. 237-97, 1993.

BRESSANI, R. Research needs to up-grade the nutritional quality of common beans (Phaseolus vulgaris L.). Qualitas Plantarum Plant Foods for Human Nutrition, Netherlands, v. 32, p. 101-110, 1983.

BRESSANI, R.; HERNANDEZ, E.; BRAHAM, E. Relationship between content and intake of bean poliphenolics and protein digestibility in humans. Plant Foods for Human Nutrition, Dordrecht, v. 38, p. 5-21, 1988.

COELHO, J. V. Fenólicos totais e taninos durante o desenvolvimento e o armazenamento do feijão (Phaseolus vulgaris L.). 1987. 117 f. Tese (Doutorado em Nutrição) - Universidade de São Paulo, São Paulo, 1987.

Ciênc. agrotec., Lavras. V.27, n.4, p.858-864, jul./ago., 2003 
ESTEVES, A. M. Comparação química e enzimática de seis linhagens de feijão (Phaseolus vulgaris L.). 2000. 55 p. Dissertação (Mestrado em Ciência dos Alimentos) - Universidade Federal de Lavras, Lavras, 2000 .

ELIAS, L. G.; FERNANDEZ, D. G.; BRESSANI, R. Possible effects of seed coat polyphenolics on the nutricional quality of bean protein. Journal Food Science, Chicago, v. 44, n. 2, p. 524-527, Mar./Apr. 1979.

FUKUDA, G.; ELIAS, L. G.; BRESSANI, R. Significado de algunos fatores antifisiologicos y nutricionales en la evalution biologica de diferentes cultivares de frijol comum (Phaseolus vulgaris L.). Archivos Latinoamericanos de Nutrition, Guatemala, v. 32, n. 4, p. 945-960, 1982.

GOMEZ-BRENES, R. A.; NUÑES, E. I.; BRESSANI, R. Comportamiento biologico de fracciones proteinicas aisladas del frijol comum (Phaseolus vulgaris). Archivos Latinoamericanos de Nutricion, Guatemala, v. 33, p. 79-90, 1983.

HAGERMAN, A. E.; BUTLER, L. G. Condensed tannin purification and characterization of tanninassociated proteins. Journal of Agricultural and Food Chemistry, Washington, v. 28, n. 4, p. 947-952, Jul./Ago. 1980.

HERNÁNDEZ, M.; LA VEJA, A.; SOTELO, A. Determination de la digestibilidad proteinica in vitro e in vivo en cerais y leguminosas, crudos e cocidos. Archivos Latinoamericanos de Nutrición, Caracas, v. 34, n 3, p. 513-522, 1984.

LAJOLO, F. M.; GENOVESE, M. I.; MENEZES, E W. Qualidade Nutricional. In: ARAÚJO, R. S.; AGUSTÍN RAVA, C.; STONE, L. F.;
ZIMMERMANN, M. J. de O. (Coords.). Cultura do feijoeiro comum no Brasil. Piracicaba: Potafos, 1996. p. 71-99.

LOPES, C. T. Digestibilidade "in situ" de bagaço de cana, palha de arroz, de feijão e capim Cameroon tratados termicamente. 1990. 33 f. Dissertação (Mestrado em Nutrição de Ruminantes) - Escola Superior de Agricultura de Lavras, Lavras, 1990.

MORAIS, A. R. Estatística experimental: uma introdução aos delineamentos e análise de experimentos. Lavras: UFLA, 2000.

REDDY, N. R.; PIERSON, M. D. Dry beans tannins a reviews of nutritional implications. Journal of the American Oil Chemists'Society, Champaing, v. 62, p. 541-549, Mar. 1985.

RIBÉREAU-GAYON, P. Plant Phenolics. [S.1.]: Edinbrirg T\&A Constable, 1972. 247 p.

RIOS, A. de O. Avaliação da época de colheita e do armazenamento no escurecimento e digestibilidade de três cultivares de feijão (Phaseolus vulgaris L.). 2000. 59 p. Dissertação (Mestrado em Ciência dos Alimentos) - Universidade Federal de Lavras, Lavras, 2000.

SGARBIERI, V. C.; ANTUNES, P. L.; ALMEIDA, L. D. Nutritional evaluation of four varieties of dry beans (Phaseolus vulgaris L.). Journal of Food Science, Chicago, v. 44, n. 5, p. 1306-1308, Sept./Oct. 1979.

SWAIN, T.; HILLIS, W. E. The phenolic constituints of Prunus domestica I. The quantitative analysis of phenolic constituents. Journal of Science of Food and Agriculture, London, v. 10, n. 1, p. 63-68, Jan. 1959. 